\section{La Arqueología de la Construcción. Un laboratorio para el análisis de la arquitectura de época romana}

\section{The archaeology of construction. A laboratory to analyse the architecture of the Roman period}

Antonio Pizzo

Instituto de Arqueología - Mérida*1

\begin{abstract}
Resumen
El articulo trata de los alcances obtenidos recientemente en los estudios de arquitectura romana y, concretamente, en el análisis de los procesos de construcción, gestión y organización de una obra. Se presenta un resumen de los contenidos y los primeros resultados conseguidos en los Seminarios de Arqueología de la Construcción organizados por el Instituto de Arqueología-Mérida, la Università di Siena y la École Normale Superieure de Paris. A raíz de estos seminarios se extraen una serie de problemáticas y de objetivos específicos que evidencian la peculiaridad de las temáticas relativas al reconocimiento de las dinámicas constructivas. Entre los principales aspectos tratados se documentan los elementos materiales relativos al proyecto arquitectónico, a las distintas etapas de la construcción, a las distintas técnicas constructivas y soluciones tecnológicas empleadas.
\end{abstract}

Palabras Clave: Obras; procesos y dinámicas constructivas; organización y gestión; proyecto; fases edilicias; técnicas; soluciones.

\section{Abstract \\ This paper deals with the results recently obtained within the studies of roman architecture and, mainly, within the analysis of building, management and organization processes. A summary of the contents and primary results presented to the Seminary of Archaeology of Construction organized by the Instituto de Arqueología of Mérida, the Università of Siena and the Ecole Normale Superieure of Paris is here exposed. Some issues and aims are obtained from these seminaries, showing the peculiarity of some themes related to the knowledge of building dynamics. Among the mains aspects, material elements linked with building project, different building phases, building techniques and technological solutions are highlighted.}

Keywords: Methodology of Archaeology of Architecture; Building process; Building project; Building phases.

\footnotetext{
* antoniopizzo@iam.csic.es

${ }^{1}$ Contrato posdoctoral financiado por la Junta de Extremadura, adscrito a la Università di Roma La Sapienza, Dipartamento RADAAR.
}

\section{INTRODUCCIÓN}

La «arqueología de la construcción» estudia la implantación, la organización y gestión de una obra edilicia en el ámbito de la arquitectura histórica ${ }^{2}$. Con esta definición no se quiere crear un neologismo que identifique una nueva disciplina, sino exclusivamente agrupar una serie de temáticas en relación con el análisis del mundo de la construcción en la antigüedad. En los estudios de arquitectura romana, estos argumentos han vuelto a cobrar interés en los últimos años, demostrando especial atención a las dinámicas constructivas de los edificios de época clásica.

Con el objetivo de organizar las distintas aportaciones particulares existentes y los datos sobre la arqueología de la construcción romana, se realizó en París, en febrero de 2006, un encuentro sobre las obras públicas ${ }^{3}$, en el ámbito de varias actividades de formación organizados en Ostia por la École Française à Rome, la Soprintendenza Archeologica de Ostia y la École Normale Supérieure. Este encuentro abordó la presentación de los resultados de los trabajos ostienses sobre la restitución del chantier de construction y planteó la necesidad de fomentar el desarrollo de estudios comparativos entre contextos geográficos diferentes ${ }^{4}$. El seminario resultó de gran interés ya que evidenció la existencia de relaciones y también de singularidades entre territorios y situaciones topográfico-constructivas completamente distintas. Se observó además, la ausencia de un método de análisis propio para el registro de los datos relativos a la organización de las obras edilicias, empleando en todos los casos los sistemas habituales de la arqueología estratigráfica en conexión con la gestión en bases de datos específicas.

Los antecedentes al encuentro de París, se remontan a un seminario organizado en Roma en torno a los Cantieri Antichi de la capital ${ }^{5}$, en la sede del Instituto Arqueológico Alemán en el año 2001. Este seminario se organizó en un contexto caracterizado por una actividad arqueológica frenética; las nuevas excavaciones y los proyectos de adecuación de los grandes monumentos romanos aportaron datos imprevistos sobre la organización y la construcción de los complejos monumentales públicos ${ }^{6}$. En este sentido,

\footnotetext{
${ }^{2}$ Esta definición responde a los contenidos planificados en el Plan Estratégico 2009-2013 del Instituto de Arqueología-Mérida. Se trata de una sublínea de investigación que pertenece a la línea de Arqueología de los Espacios Políticos.

${ }^{3}$ Bukowiecki, E. - Dessales, H. - Dubouloz, J. (Coords.) 2006. http://www.diffusion.ens.fr/index.php?res=cycles\&idcycle $=276$

${ }^{4}$ Las ponencias de este seminario internacional se encuentran en la pagina web señalada en la nota anterior.

${ }^{5}$ Cantieri Antichi. 2002: pp. 340-429.

${ }^{6}$ Volpe, R. 2002a: p. 339
} 
se realizaron nuevos análisis constructivos de conjuntos emblemáticos para la arquitectura romana como el Coli$\mathrm{seo}^{7}$, las Termas ${ }^{8}$ y el Foro de Trajano', orientados a establecer los procesos de gestión y la economía en obras de gran envergadura, sobre la base metodológica de las anteriores investigaciones de las termas de Caracala de J. Delaine $^{10}$.

Sin embargo, el seminario de París de 2006 constituye el marco en el que se decide integrar las distintas experiencias en un grupo de trabajo internacional vinculado a las temáticas citadas. Dicho grupo se ha materializado en la realización de una serie de tres seminarios titulados Arqueología de la Construcción. Las actividades se han celebrado en Mérida en Octubre de 2007, en Siena en Noviembre de 2008 y en París programado para Diciembre de $2009^{11}$.

El objetivo principal de este proyecto es reunir temática y geográficamente una serie de cuestiones constructivas sobre la arquitectura clásica que, raras veces, ocupan un lugar propio en las distintas monografías. Dichas cuestiones han servido, generalmente, como elemento colateral al análisis de un edificio clásico, utilizándose como aportaciones secundarias para tesis de carácter muy amplio sobre el estilo de la arquitectura antigua.

En el caso más específico de la arquitectura romana son numerosos los estudios que reflejan la caracterización de los aspectos estilísticos, tipológicos y cronológicos mientras que, en raras ocasiones, se abordan los motivos urbanísticos, económicos y técnicos que llevan a la construcción de un edificio. Los únicos elementos estudiados de la tecnología edilicia se refieren a las técnicas constructivas, analizadas como un elemento más de un estilo arquitectónico, lejos de una visión analítica que atienda a la dinámica productiva, las modalidades, los tiempos y la organización del trabajo, los sistemas de aprovisionamiento de los materiales o la calidad y cantidad de mano de obra.

Desde la organización de los seminarios de «arqueología de la construcción» se ha querido focalizar la atención en estos últimos aspectos y contrastar la idea de que los

\footnotetext{
${ }^{7}$ Rea, R. - Beste, H. J. - Lancaster, L. 2002: pp. 341-375.

${ }^{8}$ Volpe, R. 2002b: pp. 377-394.

${ }^{9}$ Bianchi, E. - Meneghini, R. 2002: pp. 395-417.

${ }^{10}$ Entre los trabajos de J. Delaine se recuerdan sus aportaciones a la arqueología de la construcción en Delaine, J. 1997; Delaine, J. 2003: pp. 723-732; Delaine, J. 2007: pp. 237-252.

${ }^{11}$ En la organización colaboran el Instituto de Arqueología que, además, financia las tres publicaciones de las actas, la Universidad de Siena (Dipartimento di Archeologia e Storia delle Arti) y la École Normal Supérieure de Paris. En la actualidad se ha editado el primer volumen de la serie (Camporeale, S. Dessales, H. - Pizzo, A. (eds.) 2008), mientras que el segundo se encuentra en prensa (Camporeale, S. - Dessales, H. - Pizzo, A. (eds.) 2009 e.p.).
}

edificios son el fruto de proyectos generales que se concretan de forma estandarizada en las distintas ciudades. Esta visión tiene orígenes historiográficos evidentes, reconocibles en la escasez de bibliografía vinculada con la tecnología de la construcción romana ${ }^{12}$.

\section{ANTECEDENTES}

H. Dessales ha realizado, recientemente, un ensayo sobre la definición de Arqueología de la Construcción para el caso de Ostia ${ }^{13}$, a partir de la selección de una parte de la bibliografía en relación con los aspectos constructivos de la arquitectura de la ciudad. Una de las primeras conclusiones que se extraen de esta reflexión es la evidencia de las reducidas contribuciones a la temática edilicia que, en general, presentan un panorama desequilibrado respecto al análisis artístico de la arquitectura de época romana.

En este sentido, la arqueología clásica española no se disocia de estas tendencias generales y es posible citar solamente casos muy puntuales de una visión técnica de la arquitectura. Se recuerdan los trabajos desarrollados en el Departamento de Prehistoria y Arqueología de la Universidad Autónoma de Madrid, dirigidos por M. Bendala, sobre varias ciudades de la Bética ${ }^{14} \mathrm{y}$ de la Lusitania ${ }^{15}$, recurriendo sistemáticamente a un procedimiento de registro estructurado sobre el examen de las técnicas constructivas.

De forma tangencial a nuestros planteamientos es oportuno considerar las aportaciones promovidas desde la organización de los Congresos de Historia de la Construcción ${ }^{16}$. Estas iniciativas han resultado de cierto interés para fomentar la reunión de experiencias disciplinares muy distintas en torno a la temática de la construcción, sin embargo el material presente en las publicaciones se caracteriza por un amplio número de aportaciones relativas a la época moderna, planteadas sistemáticamente sin una metodología arqueológica concreta y con una atención particular a las fuentes escritas.

\footnotetext{
12 Con esta finalidad estamos preparando una nueva monografía de carácter historiográfico relativa a las causas y modalidades que llevaron los estudios de arquitectura romana desde una visión tecnológica a un viraje hacia la historia del arte.

${ }^{13}$ Dessales, H. 2008: p. 21. En esta ocasión se ha dado una buena definición de la arqueología de la construcción, en relación con los contenidos de las actividades citadas con anterioridad: "archéologie de la construction ", qui nous semble évoquer, mieux peut-être que la notion de bâti, l'idée d'une pratique active : le cycle productif des matériaux, les diverses chaînes opératoires de la conception à la réalisation du monument permettent de révéler l'organisation fonctionnelle $d u$ chantier, dans ses aspects sociaux, culturels et économiques.

${ }^{14}$ Roldán Gómez, L. 1987, 1992, 1994.

${ }^{15}$ Durán Cabello, R. 1991-1992, 1998, 2004; Bendala, M. 1992, Bendala, M. Dúran, R. 1994; Bendala, M. - Rico, C. Roldán, L. (Eds.) 1998; Rodríguez Gutierrez, O. 2004.
} 
El problema reside en la misma definición de Historia de la Construcción. La óptica general de los historiadores sin ánimo de polémica dado que se trata de un problema metodológico muy antiguo - utiliza los objetos, y concretamente el objeto arquitectónico para contrastar e interpretar los documentos escritos. Con esta premisa es difícil comprender el potencial de información contenido en las estructuras y sobre todo definir la importancia de las mismas en la reconstrucción del proceso histórico y constructivo de un edifico.

Este alejamiento de la visión arqueológica de la construcción genera trabajos sobre la evolución de determinados sistemas edilicios, perdiendo, por otro lado, los datos relativos a las dinámicas y a la organización de los procesos constructivos, comprensibles, en nuestra opinión, solamente mediante una visión estratigráfica de la arquitectura.

Estos distintos planteamientos, incapaces de organizarse conjuntamente, debido a su discordancia metodológica, han generado una dispersión de las distintas aproximaciones a la temática de la construcción. En este sentido, con la organización de los encuentros de «arqueología de la construcción», se fomenta una integración en el ámbito de un mismo contenedor teórico y metodológico, visto que el objeto final del estudio es la arquitectura, y la problemática constructiva es similar en las distintas épocas históricas.

En cambio, este proceso de dispersión se ha conseguido evitar, en la «nueva arqueología medieval», quizás por el hecho de volcarse desde el inicio y homogéneamente en un método estrictamente arqueológico, definido en España en los años noventa del siglo $\mathrm{XX}^{17}$, posteriormente a las conocidas aportaciones italianas ${ }^{18}$ y de forma paralela a diferentes experiencias europeas ${ }^{19}$. En este contexto se ha conseguido establecer un cambio radical respecto a las lecturas limitadas a la comprensión histórica de un edificio concreto y se han orientado los estudios hacia una investigación muy rigurosa que contempla la inserción de monumentos emblemáticos en la óptica más amplia de la historia de una ciudad o de una región ${ }^{20}$. Al rigor del

${ }^{16}$ Casas Gómez, A. et alii (eds) 1996; Bores Gamundi, F. et alii (eds) 1998; Graciani García, A. 2000 et alii (eds); Huerta Fernández, S. (ed.) 2003; Huerta Fernández, S. (ed.) 2005; Dunkeld, M. et alii (eds) 2006; Arenillas, M. et alii (eds.) 2007.

${ }^{17}$ Caballero Zoreda, L. 1996: pp. 55-74; Caballero Zoreda, L. - Fernández Mier, M. 1997: pp. 147-158; en general véase Caballero Zoreda, L. - Escribano Velasco, C. 1996.

${ }^{18}$ Brogiolo, G. P. 1988; Francovich, R. - Parenti, R. (Eds.) 1988; Parenti, R. 1988.

${ }^{19}$ Journot, F. 1999: pp. 133-163; Pringent, D. - Hunot, J. Y. 2000: pp. 72-75; Wood, J. 1994; Morriss, R. K. 2000; Roskams, S. (Ed.) 2000.

${ }^{20}$ Azkarate Garai-Olaun, A. 2002: pp. 55-71; en general Azkarate, A. - Cámara, L. - Lasagabaster, J. A. - Latorre, P. 2001 marco teórico sobre la metodología empleada ${ }^{21}$ y a la difusión temprana «en español» de la praxis estratigráfica ${ }^{22}$, se han asociado estudios sobre las técnicas constructivas de época altomedieval realizados con el objetivo de solucionar cuestiones históricas ${ }^{23}$ o sistematizar los procesos de actuación en el registro de los edificios históricos ${ }^{24}$.

Desafortunadamente estas sistematizaciones no se han producido todavía en el campo de los estudios de arquitectura romana, considerándose éste uno de los objetivos principales de la «arqueología de la construcción».

Tratándose en la actualidad de un laboratorio abierto y lejos de una formalización teórico-metodológica propia, la «arqueología de la construcción» ha asimilado distintas aportaciones científicas que intentan reconstruir, con método arqueológico, las etapas de las operaciones que acompañan la construcción de un edificio y la organización de la misma obra. Estas operaciones pertenecen a un concepto que ha sido objeto de discusión en el primer encuentro de Mérida: chantier, cantiere, obra. Una buena definición es la que propone F.C. Giuliani: «Il cantiere è un concetto imparziale che non distingue l'opera di grande impegno da quella di modesta levatura. È l'insieme dei condizionamenti posti dai problemi fisici e dalle risposte metodologiche, degli accorgimenti tecnici messi a punto dall'uomo per risolverli». El análisis de estos condicionamientos «spinge a conoscere le caratteristiche costruttive e funzionali degli oggetti ${ }^{25}$.

En el ámbito de esta definición se incluyen distintas fases de un proceso constructivo: el proyecto inicial; la preparación del área edificable; las obras de infraestructuras vinculadas con el desarrollo de los trabajos; la adquisición y elaboración de los materiales constructivos; las tareas constructivas; los acabados y las decoraciones; las alteraciones y reformas de un contexto construido ${ }^{26}$; la difusión de las prácticas constructivas en los distintos lugares del imperio; la identidad y entidad de los promotores y ejecutores de las obras analizadas en el campo de la arquitectura pública y privada; la circulación de la mano de obra ${ }^{27}$; las relaciones entre las distintas tipologías de los materiales; la capacidad de construir con conocimientos tecnológicos aparentemente estandarizados y la dimensión económica de la obra.

\footnotetext{
${ }^{21}$ Caballero Zoreda, L. 2002: pp. 83-100.

${ }^{22}$ Caballero Zoreda, L.1987: pp. 13-58.

${ }^{23}$ Caballero Zoreda, L. 1999: pp. 221-233; Azkarate, A. - Quirós, J. A. (eds.) 2005.

${ }^{24}$ Caballero Zoreda, L. 2004: pp. 127-143

${ }^{25}$ Giuliani, F. C. 2002: p. 427.

${ }^{26}$ De Laine, J. 2008: pp. 321-328.

${ }^{27}$ Camporeale, S. - Dessales, H. - Pizzo, A. 2008: p.12.
} 
La idea principal de los encuentros de «arqueología de la construcción» pretende analizar específicamente los componentes de este proceso, operando paralelamente una comparación entre las dinámicas constructivas de Roma y las provincias occidentales y orientales.

\section{RELACIÓN METODOLÓGICA CON LA ARQUEOLOGÍA DE LA ARQUITECTURA}

La metodología de la «arqueología de la construcción» se basa en el reconocimiento de los elementos materiales que informan de la organización y gestión de una obra edilicia, empleando métodos y sistemas de registro que no se diferencian de la arqueología estratigráfica.

En el campo de la arqueología medieval ya se ha evidenciado la importancia del análisis de los aspectos constructivos como paso previo al conocimiento de los edificios. La atención de los arqueólogos medievales se ha concentrado, desde hace tiempo ${ }^{28}$, sobre la investigación de los materiales y las técnicas edilicias ${ }^{29}$, advirtiendo la necesidad de instaurar una relación entre la arquitectura del medioevo y la creación de tipologías edilicias a escala regional y subregional ${ }^{30}$. Sin embargo, la formación de instrumentos tipológicos y cronológicos a escala territorial $^{31}$, base del conocimiento cuantitativo de los contextos construidos $^{32}$, se ha reducido, en nuestra opinión, en favor de un mayor perfeccionamiento de las técnicas de registro de las unidades estratigráficas, las lecturas de los paramentos de los edificios históricos medievales y la relación entre arqueología de la arquitectura y restauración ${ }^{33}$.

Solo recientemente, después de un largo periodo protagonizado por la consolidación de las practicas metodológicas $^{34}$, se ha vuelto, desde el mismo contexto, a sugerencias muy interesantes sobre el estudio de los aspectos constructivos y a los muros, considerados como «la struttura materiale per eccellenza ${ }^{35}$.

En el ámbito de la arqueología de la arquitectura se han abordado, además, elementos de gran importancia para la definición de las distintas formas de construir en contextos territoriales distintos ${ }^{36}$, consiguiendo, desde el

${ }^{28}$ Caballero Zoreda, L. 1987: pp. 13-58.

${ }^{29}$ Mannoni, T. 1974: pp. 291-300.

${ }^{30}$ Brogiolo, G. P. 1996: p. 12.

31 Existen, en este sentido, trabajos puntuales relacionados con proyectos concretos de creación de atlantes de técnicas constructivas a escala regional y local. Véase por ejemplo: Mannoni, T. 1974: pp. 291-300; Parenti, R. 1988: pp. 249-279; Brogiolo; G. P. - Zonca, A. 1989: pp. 37-44.

${ }^{32}$ Utrero, M. ${ }^{a}$ Á. 2008: p. 101.

${ }_{33}$ Brogiolo, G. P. 2002: pp. 19-26.

${ }^{34}$ Caballero Zoreda, L. 1996: pp. 55-74; Caballero Zoreda, L. 2002: pp. 83-100.

${ }^{35}$ Parenti, R. 2002: p. 73.

${ }^{36}$ Caballero Zoreda, L. 1999: pp. 221-233. punto de vista histórico, la comprensión de eventos relativos, por ejemplo, a la movilidad de la mano de obra en un contexto regional o nacional, a la transmisión de los conocimientos tecnológicos ${ }^{37}$, al papel de los promotores en la financiación de las obras o a la elección del grado de especialización de los ejecutores, etc. La comprensión de estos detalles deriva de un proceso de estudio muy lento y riguroso basado en los tipos de herramientas utilizados ${ }^{38}$, los contratos de asignación de obras, el análisis de las superficies de los elementos constructivos, arquitectóni$\cos ^{39}$ o decorativos.

Sin embargo, a pesar de la atención prestada a estos elementos de la construcción escasean las aportaciones directas a la «archeologia del cantiere» ${ }^{40}$ como sector específico de la investigación ${ }^{41}$. El análisis de estos factores constituye, en cambio, el aspecto principal de la «arqueología de la construcción» en época romana.

La especificidad de esta temática no es de nuestra invención y se sostiene con argumentos propios desde la misma arqueología de la arquitectura. En un articulo de gran interés publicado por T. Mannoni y A. Boato en el año 2002, en las Actas del Seminario Internacional de Arqueología de la Arquitectura de Vitoria ${ }^{42}$, se hace referencia a las potencialidades del análisis de la obra de construcción como sector de investigación propio, vinculado con la Arqueología de la Arquitectura y sin embargo perceptible, también, desde la historia económica. La definición del estudio de una obra se contempla desde el punto de vista de las "prospettive di ricerca che esso offre all'insieme delle discipline archeologiche e storiche, che si occupano del costruito. Quest'ultimo è senza dubbio da intendersi nel senso più ampio: non parti in elevato autonome e autonomamente indagabili, ma 'contesto' complessivo" ${ }^{43}$.

En este sentido, es evidente que el uso del registro estratigráfico resulta fundamental para comprender las dinámicas de una obra y el contexto al que pertenece. Un proceso constructivo es por definición estratigráfico, tratándose básicamente de una superposición de operaciones diarias, semanales o mensuales que dejan una amplia serie

\footnotetext{
${ }^{37}$ Bianchi, G. 1996: pp. 53-64;

${ }^{38}$ Bessac, J. P. 1986; Hobel, S.E. 1989: pp. 263-290; Bianchi, G. 1997: pp. 2537; Bessac, J. P. 1999: pp. 9-52; Bessac, J. C. - Burnouf, J. - Journot, F. - Prigent, D. - Sapin, C. - Seigne, J. 1999.

${ }^{39}$ Gabbrielli, F. 1996: pp. 17-40; Utrero Agudo, M. a Á. 2006.

${ }^{40}$ Mannoni, T. - Boato, A. 2002: p. 45.

${ }^{41}$ Una aportación en este sentido en Caballero Zoreda, L. - Murillo Fragero, J. I. 2004: pp. 39-56.

${ }^{42}$ Mannoni, T. - Boato, A. 2002: pp. 39-53.

${ }^{43}$ Mannoni, T. - Boato, A. 2002: p. 44.
} 
de improntas en las estratificaciones horizontales y verticales de un edificio o de su contexto (el ámbito de la obra). En la reconstrucción de las actividades de una obra edilicia adquiere particular importancia la sucesión estratigráfica de los contextos horizontales asociados, debido a la capacidad de restituir los signos materiales de las actividades edilicias previas y coetáneas al uso de la estructura. En muchos casos, se trata solamente de las últimas operaciones constructivas (materiales y restos de morteros no utilizados; elementos constructivos esbozados, parcialmente elaborados; elementos para la organización de la obra; estructuras funcionales de su gestión, etc.). La comprensión de estos signos, a menudo ignorados en las excavaciones de época romana, permite cuantificar cada una de las operaciones con el objetivo de aproximarse a la definición del ritmo y los tiempos de la construcción.

El análisis estratigráfico vinculado a la formulación tradicional de unidades, fases y periodos, puede no ser exhaustivo si nos ocupamos de reconstruir las dinámicas y los tiempos del trabajo en una obra. Por ejemplo, el podio de un templo realizado con opus caementicium y revestido con sillería de granito presentará varias unidades estratigráficas que «se unen» formando un determinado numero de actividades, una fase y un periodo. Si el interés se desplaza a la organización de la obra edilicia, en el ámbito de las mismas unidades estratigráficas coexistirán un número distinto de unidades de trabajo, preparación y vertidos de hormigón, elaboración y colocación de la sillería, acabados superficiales. Estos elementos constituyen el centro de la atención de la «arqueología de la construcción», detalles que implican, quizá, nuevas reflexiones sobre algunos conceptos tradicionales. En el caso de un edificio romano monumental, fruto de un proyecto único, es más lógico definir distintas «unidades de trabajo» ${ }^{44}$, fundamentales para la reconstrucción del proceso de construcción y, sin embargo, poco consideradas en un análisis estratigráfico tradicional centrado en la caracterización de las transformaciones de un edificio ${ }^{45}$.

En esta línea es necesaria otra puntualización sobre la peculiaridad de las construcciones de época romana. Una parte de estos edificios presenta un estado de conservación fosilizado en el momento de abandono o destrucción voluntaria de sus estructuras. La tarea de distinción de unidades estratigráficas, actividades de replanteamiento o

\footnotetext{
${ }^{44}$ Mannoni, T. - Boato, A. 2002: p. 45.

${ }^{45}$ En este sentido existe ya una propuesta de vincular las unidades relativas a la obra edilicias con una "Fiche d'Unité Stratigraphique Construite». Véase Bukowiecki, E. - Dessales, H. 2008: p. 25; y anteriormente en el ámbito de la misma arqueología medieval, Paron-Kontis, I. 2005: pp. 13-18.
}

remodelación, resulta difícil de establecer en contextos que, en la mayoría de los casos, presentan un aspecto que denota la conservación de un único proceso constructivo. En estos casos, la lectura estratigráfica redunda en el registro de un mecanismo productivo homogéneo correspondiente al uso del edificio, sin posibilidad de articular una historia del mismo. A pesar de la escasa complejidad estratigráfica típica de varios conjuntos monumentales de época romana, se reconoce la utilidad de seguir los pasos canónicos para la lecturas de las características técnicas de los edificios a través del análisis estratigráfico, aunque en la mayoría de los casos estas lecturas sirven para establecer, «únicamente», los pasajes de las distintas fases constructivas de las estructuras, potenciando el estudio del edificio con los detalles de tipo técnico relativos al proceso de edificación.

Se trata simplemente de revisar o adaptar la praxis operativa del mismo método, sin modificarlo desde el punto de vista teórico.

De acuerdo con esta premisa, la «arqueología de la construcción» es una fórmula complementaria que se integra en el cuadro general de la arqueología de la arquitectura, respondiendo, en ciertos casos, al problema de la complejidad estratigráfica de los alzados (escasa en los edificios romanos abandonados en época antigua) y a su vinculación con el reconocimiento del proceso constructivo. Desde el punto de vista metodológico, es fundamental extender estas líneas de trabajo a varios campos relacionados con el mundo de la arquitectura de época histórica, una vez demostrada cierta limitación en las definiciones que se orientan solamente a la critica de los estudios de carácter estilístico o al examen de los restos en alzado $^{46}$.

Si la Arqueología de la Arquitectura es indispensable para la reconstrucción de la historia del edificio o de un conjunto monumental, la «arqueología de la construcción» caracteriza las pequeñas historias relacionadas con los protagonistas de la construcción.

Es necesario empezar un proceso de adaptación de la estratigrafía a las exigencias concretas del estudio constructivo, según los parámetros que indican las mismas estructuras, condicionadas por su estado de conservación, degradación, condicionamientos geográficos, etc. Solo estratigráficamente es posible reconstruir la historia de una obra, analizando las modalidades de su progresión en un determinado arco temporal, desde la realización de las cimentaciones hasta las cubiertas o los detalles de acabados y

\footnotetext{
${ }^{46}$ Esquieu, Y. 1997: p. 133.
} 
revestimientos ${ }^{47}$. En este sentido, el registro estratigráfico es fundamental como instrumento para definir la secuencia diacrónica de los cuerpos de fábricas o de los elementos estáticos que conforman un edificio. La cuestión reside en el nivel de profundización del tipo de lectura estratigráfica. En el caso de los análisis que se han efectuado en las aportaciones a la «arqueología de la construcción» romana se ha operado con dos distintos criterios, dictados por la complejidad de los mismos monumentos.

La escala de valores empleada varía desde a) las simples observaciones estratigráficas sobre la cronología relativa entre técnicas constructivas, tipos o variantes, b) o la realización de lecturas de paramentos de edificios estratigráficamente complejos, con valoraciones estratigráficas puntuales de grupos de estructuras o ámbitos arquitectónicos.

Resultaría complejo reconstruir la organización de una obra sin el conocimiento previo de la extensión espacial y temporal de las sucesiones de operaciones que conforman las fases constructivas. Por tanto un análisis estratigráfico ayuda notablemente en la definición del marco espacial (los distintos ámbitos de un edificio) y temporal en los que intervienen los constructores, dando indicaciones imprescindibles en el ámbito de la organización de las obras, referidas a la totalidad del edificio o a secuencias relativas al montaje de un único elemento arquitectónico.

En el mismo ámbito de la Arqueología de la Arquitectura se ha planteado la posibilidad de observar la historia de una obra edilicia bajo dos perspectivas distintas: la primera relativa a las modalidades de sucesión temporal de la obra; la segunda relativa a la organización de la misma. En el primer caso resulta fundamental la aproximación estratigráfica sin cuyos datos sería impensable reconstruir la dinámica de construcción de un edificio respecto a las distintas partes estructurales que lo forman; mientras que en el segundo, se hace referencia al concepto de indicadores para remontarse a los distintos momentos y aspectos de la organización de la obra ${ }^{48}$. A menudo, el estado de conservación de los edificios de época romana permite orientar la atención solamente hacia los indicadores, reconocibles en contextos homogéneos pertenecientes a una actividad estratigráfica coherente, o a estratos asociados a los edificios y a la implantación misma de la obra.

Esta visión que focaliza su atención en la determinación del proceso constructivo se alimenta del análisis estratigráfico y lo enriquece, añadiendo a las cronologías relativas de los contextos una amplia serie de nociones

\footnotetext{
${ }^{47}$ Mannoni, T. - Boato, A. 2002: p. 44.
}

${ }^{48}$ Mannoni, T. - Boato, A. 2002: pp. 45-46. sobre la organización, la gestión y la economía del trabajo en el mundo antiguo.

El retraso existente en la difusión de estas prácticas en la arqueología clásica nos ha llevado a una revisión de nuestras perspectivas de estudio y a la definición de una serie de objetivos que, en esta fase, nos han ayudado a reorganizar un campo disciplinar con escasa consideración científica y a fomentar el empleo de estas prácticas metodológicas para el análisis de la arquitectura romana. La intención es producir un giro sustancial en la aproximación metodológica, fomentando la aplicación de un proceso de documentación que, en los últimos decenios, ha generado un cambio muy positivo en la arqueología medieval.

\section{OBJETIVOS GENERALES}

El objetivo general se centra en el análisis de los aspectos técnicos y organizativos de las actividades edilicias, no excluyendo los procesos de registro que puedan orientarse a conjuntos monumentales de diferente época histórica. Como ya se ha indicado, este tipo de análisis que ha caracterizado el desarrollo de la arqueología medieval en los últimos treinta años, sin embargo no ha influenciado suficientemente la investigación en la arquitectura clásica, involucrada, salvo algunos casos, en la determinación de estilos constructivos, tipología de decoraciones arquitectónicas y programas iconográficos.

Durante muchos años la investigación ha buscado una coincidencia entre un modelo preestablecido y la realidad material de la arquitectura romana, más que realizar un trabajo homogéneo y sistemático de registro apoyado en la integración de los datos materiales evidentes en los restos arquitectónicos conservados. Es necesario, en este sentido, volver un paso «atrás» y observar con mayor detalle y atención la fuente material para contrastar, una vez recogidos datos de distintas orígenes, la adhesión a los modelos conocidos.

Cuando se analiza un edificio desde un punto de vista técnico-constructivo se observa que muchas de las tipologías y cronologías preestablecidas chocan con los imprevistos y los cambios de las dinámicas edilicias. Las soluciones especificas condicionadas por la topografía de los terrenos, los materiales, las técnicas ${ }^{49}$, los promotores, las posibilidades económicas y las ya existentes especulaciones reducen o amplían los tiempos de ejecución, modificando sustancialmente las cronologías absolutas definidas por la epigrafía o

\footnotetext{
${ }^{49}$ Sobre la praxis operativa de la mano de obra y como incide en la producción de una determinada técnica véase Giuliani, F. C. 2002: p. 428.
} 
los programas decorativos de un determinado edificio. En la realización y finalización de un proyecto, condicionamientos de este tipo pesaban más que la voluntad del emperador o de otro promotor.

Con estas premisas se recurre a la clasificación y a la consecuente ordenación tipológica de las técnicas y de los elementos relacionados con los procesos constructivos, reconociendo que ambos niveles de la investigación representan solamente el primer estadio hacia una lectura más completa, no limitada al panorama constructivo, sino ampliada a la definición de la cultura arquitectónica de un territorio.

Otro de los objetivos es completar los estudios de arquitectura antigua, tradicionalmente orientados a las tipologías monumentales, a los elementos decorativos o a las relaciones entre arquitectura y sociedad y crear una red de intercambio de datos en relación con estos argumentos. Este aspecto presenta una desventaja desde el punto de vista espacial, visto que las obras públicas de Roma han sido objeto de importantes estudios, mientras que las provincias (Hispania en particular) permanecen todavía como un territorio pendiente.

En la perspectiva de crear un vínculo de tipo metodológico entre las distintas áreas geográficas y los diferentes campos de la edilicia antigua, nuestro planteamiento intenta comprender, en lugares y contextos distintos, las peculiaridades de la realización de cada una de las obras, la difusión de las prácticas constructivas provinciales, la circulación de mano de obra, los niveles tecnológicos regionales alcanzados y las eventuales interrelaciones entre las distintas áreas del mundo romano.

Con el objetivo de reconstruir los procesos de organización, producción y gestión de las obras, la intervención puede priorizar diferentes tipos de fuentes y de aproximaciones: condiciones jurídicas relativas a la preparación y prosecución de las obras (contratos, condiciones del trabajo, elección de la mano de obra), contextos sociales y económicos (actos de evergetismo, financiación pública o privada, intervención del ejercito), aspectos relacionados con el proyecto arquitectónico (intervención del arquitecto, promotores, preparación de la obra mediante trazados), aspectos constructivos (construcciones, demoliciones, reutilizaciones) a partir del análisis de los materiales empleados (aprovisionamiento del material, transporte, elaboración) o de las técnicas constructivas (cimentaciones, estructuras en alzado, sistemas de cubiertas, sistemas de posicionamiento - maquinas de elevación, andamios, etc. $)^{50}$.

${ }^{50}$ Camporeale, S. - Dessales, H. - Pizzo, A. 2008: p.12; Delaine, J. 1997.
El registro de estos datos técnicos sirve, en esta primera etapa, para la implantación de un debate nuevo sobre la importancia del análisis de las obras en el estudio de los sistemas constructivos en relación con las sociedades de distintas áreas del territorio romano.

Nos ha parecido necesario fomentar la idea de recuperar los datos puntuales y detallados sobre la construcción de un edificio, respecto a la tendencia a plantear hipótesis de carácter general que, si por un lado, nos ayudan a comprender el marco histórico de determinadas estructuras, por otro facilitan la pérdida de las informaciones que llevaron a la realización de las mismas, sus problemáticas técnicas y urbanísticas.

La tendencia a establecer las modalidades y los tiempos de una obra no es solamente una aproximación técnica a la arquitectura clásica, sino también un acercamiento histórico fundado en la reconstrucción de la evolución de un proceso constructivo; y en la comprensión de mecanismos más generales como los cambios en el empleo de los materiales, las diferencias en el uso de distintas técnicas constructivas o la transmisión de los conocimientos tecnológicos.

En general, la historia de un edificio se considera desde la óptica de su realización, prestando particular atención a las soluciones técnicas empleadas en la edificación de estructuras aparentemente estandarizadas.

En el análisis técnico-constructivo y en el registro arqueológico de los edificios se considera el impacto de incidencias de distinto tipo: presencias de restos arquitectónicos previos en el solar a edificar, con consecuente adaptación y reorganización del proceso constructivo; demoliciones totales o parciales; integración de espacios con funcionalidades distintas.

Entre los elementos más significativos para la reconstrucción del proceso organizativo de una obra destacan:

1. Elementos de reconocimiento del proyecto arquitectónico.

2. Informaciones sobre las distintas etapas de desarrollo de la obra de construcción, desde la implantación hasta su finalización.

3. Técnicas de construcción homogéneas o diversificadas en el ámbito de la misma estructura.

4. Presencia de elementos para la gestión de la obra (mechinales para el montaje de los andamios; huellas del desmontaje de cimbras de $\operatorname{arcos} y$ bóvedas; estructuras funcionales del desarrollo del proceso constructivo).

5. Diferencias técnicas entre soluciones aparentemente similares.

6. Errores de cálculo en las fases de obra y reajustes. 
Entre estas operaciones vinculadas al desarrollo de una obra es posible plantear una división ulterior respecto a las etapas mismas del trabajo, distinguiendo por ejemplo las actividades referidas a una obra específica antes de la construcción (estudio de la situación previa a la ocupación de un determinado solar; trabajos de demolición, nivelación, preparación del área y creación de infraestructuras funcionales de la obra misma); las operaciones intrínsecas a la obra (reconstrucción completa del ciclo edilicio, desde el aprovisionamiento de los materiales hasta la realización de las estructuras); y aquellas derivadas por el desarrollo de las tareas de construcción (impacto ambiental de la obra en la gestión de la ciudad; cierre y aperturas de nuevos recorridos; admisión de nueva mano de obra; gestión de los residuos, etc. $)^{51}$.

Estos elementos, analizados a lo largo de los seminarios citados, plantean otra serie de cuestiones colaterales que interactúan con las anteriores y, en muchos casos, permiten su identificación. Se trata, en síntesis de los aspectos vinculados con:

a. Las condiciones previas de las áreas edificables y la programación de una obra.

b. La reconstrucción de la entidad de los trabajos previos para el acondicionamiento de los solares, a menudo invisibles bajo la monumentalidad de las construcciones.

c. Los procesos de extracción, adquisición, trasformación y transporte de los materiales constructivos (ciclo productivo de los materiales).

d. El reconocimiento de los protagonistas de la construcción (¿quiénes? Desde la promoción imperial hasta la mano de obra de esclavos). Organización y subdivisión de los equipos de trabajo. Reconocimiento y comparación de los distintos grupos.

e. La evaluación de las cantidades de mano de obra empleadas (¿cuánto?).

f. El establecimiento de los tiempos de realización (¿durante cuánto tiempo?), fundamental para la definición de la cronología de un edificio.

El análisis de estos otros factores conduce directamente a consideraciones de carácter social y económico que, en la arqueología clásica actual, son territorio exclusivo de la epigrafía y del estudio de las fuentes escritas. Analizando estos aspectos de la arquitectura es posible completar las

\footnotetext{
${ }^{51}$ Agradezco las notas de los evaluadores de este artículo para esta visión de las
} etapas de obra. conclusiones tradicionales con la reconstrucción de los procesos, los autores y los detalles de un contexto que, en la mayoría de los casos, permanece oculto bajo la comprensión del fenómeno histórico general.

\section{EL PAPEL DE LAS REUNIONES CIENTÍFICAS SOBRE ARQUEOLOGÍA DE LA CONSTRUCCIÓN Y ALGUNOS RESULTADOS ESPECÍFICOS}

A pesar de estas dificultades, en el ámbito de los seminarios organizados se han alcanzado una serie de resultados que, en nuestra opinión, cambian la perspectiva futura y la óptica del estudio de la arquitectura de época romana. La serie de aportaciones recibidas en las reuniones de Mérida y Siena han devuelto protagonismo a los aspectos estrictamente relacionados con la producción de la arquitectura, ilustrando una gran cantidad de elementos y de características vinculadas, en esta primera etapa, con la organización y gestión de las obras. En este sentido, es útil entrar en los contenidos de estos aspectos y analizar brevemente la peculiaridad de algunas de las aportaciones presentadas.

Para la reconstrucción de un proceso constructivo se han empleado los mismos indicadores definidos por $\mathrm{T}$. Mannoni y A. Boato, ampliando, en cambio, el campo relativo a las fuentes documentales y limitándonos, por obvias razones, a las estructuras en mejor estado de conservación. Respecto a los elementos de reconocimiento establecidos en el articulo del año $2002^{52}$ es necesario añadir algunos factores determinantes en el reconocimiento de un proceso constructivo de época romana.

Los documentos, por ejemplo, se limitan a las fuentes escritas, a las epigráficas, incluyendo las indicaciones numerales para el montaje de elementos arquitectónicos o decorativos y las marcas de cantería. Las primeras sólo en casos específicos nos orientan a la comprensión de los mecanismos edilicios. Recogen proyectos de gran magnitud o decisiones políticas generales que determinan la planificación de una obra, no entrando casi nunca en detalles para la reconstrucción de las dinámicas de la obra. Las fuentes epigráficas que pertenecen directamente a un contexto construido indican elementos no descifrables con la sola arqueología estratigráfica. Nos informan de los

\footnotetext{
52 Véase el amplio listado de elementos de reconocimiento (indicadores) en Mannoni, T. - Boato, A. 2002: pp. 46 ss. Entre los elementos principales para la comprensión de un "cantiere», se indican los resultados extraíbles por ejemplo desde la diferenciación de materias primas de nueva extracción o reutilizadas; las dimensiones de los materiales y la influencia de las vías de comunicación; la capacidad de carga de hombres y animales; las técnicas edilicias y el reempleo de materiales procedentes de otra fase del proceso productivo; la disposición y reconstrucción de los andamios y las cimbras para la puesta en obra de las estructuras; el reconocimiento de las etapas del trabajo; etc.
} 
grandes y pequeños promotores de la industria edilicia y, sobre todo, ayudan a comprender la magnitud de una obra, diferenciando el tipo de participación pública o privada. Con la epigrafía es posible reconocer además arquitectos, albañiles, promotores improvisados, programas constructivos sistemáticos, intervenciones de reforma y reconstrucción.

Las fuentes arqueológicas se limitan, en cambio, a los elementos construidos y conservados. Los detalles de la obra relativos a las estructuras perdidas de maderas, parte fundamental en el desarrollo de un proyecto arquitectónico (andamios, cimbras, encofrados, sistemas de cubiertas, etc.), se pueden reconstruir solamente mediante las improntas parciales visibles en los alzados, no existiendo elementos reales para la comparación. Respecto al estudio de una obra de época medieval y moderna en la que se conservan un número más amplio de elementos estructurales de las cubiertas, con los distintos sistemas de suspensión de vigas y otros elementos portantes, es difícil conocer las causas que llevaron al vencimiento de los mismos o la evolución, por ejemplo de los sistemas de anclajes de las distintas partes. En este sentido, inevitablemente se pierde una parte importante de la obra y es necesario intentar una reconstrucción por aproximación y comparación con los sistemas tradicionales conocidos.

Desde el punto de vista metodológico se ha evidenciado cómo el análisis estratigráfico, combinado con los detalles de la obra, la talla de la piedra, la disposición de los elementos constructivos y, sobre todo, los estudios arqueométricos pueden restituir indicaciones asombrosamente exactas sobre la dinámica de construcción de un edificio ${ }^{53}$, añadiendo nuevos contenidos a la superposición física de las estructuras y mejorando el proceso de reconocimiento de la sucesión interna de los trabajos de edificación mediante la contextualización ambiental con el entorno.

\section{Proyecto arquitectónico}

La importancia del proyecto y sus adaptaciones han sido objeto de distintas aportaciones en relación con el urbanismo de ciudades concretas ${ }^{54}$ o edificios tipológicamente homogéneos ${ }^{55}$, considerando, en todos los casos, las etapas específicas y las peculiaridades debidas a las dimensiones de los edificios, el contexto topográfico de la obra, el planteamiento teórico general, los detalles de las proporciones geométricas, la resolución de la problemática teóri-

\footnotetext{
${ }^{53}$ Binninger, S. 2008: pp. 89-106

${ }^{54}$ Mateos, P. - Pizzo, A. 2008: pp. 243-258.

${ }_{55}$ Barresi, P. 2008: pp. 259-268.
}

co-práctica o la posibilidad de comprender los cambios efectuados respecto a los proyectos iniciales.

En muchos casos, existe una diferencia sustancial entre el proyecto arquitectónico y la consecuente praxis operativa de la obra. El registro detallado de los datos de la construcción nos permite elaborar de manera más completa una hipótesis sobre la ejecución, encontrando difícilmente los signos para el reconocimiento del proyecto original.

Resulta evidente que un objetivo futuro tiene que ser obligatoriamente la comparación y combinación de las distintas soluciones técnicas empleadas, unido a las variaciones de los proyectos en contextos y presencia de materiales diferentes para aproximarse lentamente a una historia de las innovaciones operadas en el ámbito de las técnicas constructivas.

En el ámbito del proyecto se han presentado casos de aplicación e invención de soluciones tecnológicas novedosas que sin un estudio específico de los mecanismos de organización de un cantiere permanecerían prácticamente desconocidas. Es el caso del «Emisario del Fucino», el proyecto hidráulico más importante de la antigüedad, oculto bajo otras obras del siglo XIX, incomprensible en su entidad sin el planteamiento "cantieristico» tratado durante el seminario de Mérida ${ }^{56}$.

Paolo Barresi ${ }^{57}$ ha marcado la importancia del proyecto arquitectónico con una serie de consideraciones de carácter general, recuperando las ideas de modulación de Vitruvio sobre la base del estudio modélico de M. Wilson Jones $^{58}$. La importancia de esta temática radica en la capacidad de transferir la problemática del gran proyecto arquitectónico de una obra pública y compleja a contextos «menores» caracterizados por elecciones muy peculiares ${ }^{59}$. En este contexto comparativo de la entidad de los trabajos de construcción de obras edilicias distintas se enmarca también la definición del proyecto de tipologías constructivas diferentes en una misma ciudad ${ }^{60}$. En el caso de Volubilis se ha conseguido caracterizar, por ejemplo, la organización de las obras del Arco de Caracala y de la maison aux deux pressoirs.

Desde el punto de vista temático existen grupos de edificios que se han prestado particularmente a recibir la atención de la «arqueología de la construcción». En particular se recuerdan las termas que, debido a problemáticas

\footnotetext{
${ }^{56}$ Giuliani, F. C. 2008: pp. 33-47

${ }^{57}$ Barresi, P. 2008: pp. 259-268.

${ }_{58}$ Wilson Jones, M. 2000.

${ }^{59}$ De Vos, M. 2008: pp. 269-284.

${ }^{60}$ Camporeale, S. - Papi, E. - Passalacqua, L. 2008: pp. 285-308.
} 
diversas sostenidas por la presencia de obras hidráulicas de gran envergadura, han combinado el análisis paralelo de los procesos constructivos con los sistemas de abastecimiento. No es oportuno olvidar en este sentido, que el ensayo de reconstrucción de una obra edilicia monumental como la de las termas de Caracala, publicada magistralmente por J. Delaine ha sentado unas premisas muy sólidas y un ejemplo a seguir ${ }^{61}$.

\section{Actividades previas a la ejecución de una obra}

La organización y gestión de las actividades previas y coetáneas a la implantación de una obra desarrollan un papel particular, garantizando la diversificación de las actividades edilicias entre las distintas partes de un edificio y la preparación de las áreas edificables como en el caso de la adecuación topográfica de los solares, excavaciones, nivelación del área, demoliciones, readaptación o reempleo de estructuras anteriores, trazados y materialización del nuevo proyecto arquitectónico, errores de cálculo.

Este tipo de valoración en el impacto urbanístico de una construcción en los restos existentes de una zona ya edificada ha sido analizado detenidamente en el caso de las termas de Lutteurs ${ }^{62}$, llegando a comprender la totalidad de las dinámicas de integración, adaptación e innovación del proyecto arquitectónico.

\section{Organización y gestión de una obra}

Para la reconstrucción de la organización de la obra resultan fundamentales distintas aportaciones que no pueden limitarse solamente a la lectura de las informaciones contenidas en los elementos construidos. Existe la necesidad de recuperar e integrar los datos procedentes de excavaciones arqueológicas que tengan como objetivo específico la recopilación de elementos vinculados con la obra. Normalmente, en una excavación arqueológica programada o de urgencia se pretende intervenir hasta la obtención de datos útiles a la reconstrucción de la evolución cronológica del yacimiento o de un determinado contexto. Por razones económicas o logísticas, debido a la imposibilidad de continuar excavando contextos que, o bien no pertenecen a la historia del edificio, o plantean soluciones de estabilidad del mismo por encontrarse en relación con elementos estáticos muy importantes como las cimentaciones, se recurre a la interrupción de los

${ }^{61}$ Delaine, J. 1997; entre la reconstrucción de las dinámicas constructivas de las termas se recuerdan las aportaciones de Volpe, R. 2002b; Bukowiecki, E Dessales, H. Dubouloz, J. 2008; Brissaud, L. 2008; Guyard, L. - Bertrudiére, S. - Cormier, S. Coutelas, A. 2008; Bukowiecki, E - Dessales, H. 2008b.

${ }^{62}$ Brissaud, L. 2008: pp. 107-124. trabajos. La estratificación no trasformada en estratigrafía representa, en la mayoría de los casos, el contenedor más rico de informaciones sobre los procesos constructivos y las improntas para la reconstrucción de la organización de la obra $^{63}$.

En los seminarios se han aportado nuevas informaciones relativas a detalles aparentemente poco significativos de la arquitectura antigua que, en cambio, restituyen una imagen de excepcional complejidad en el desarrollo de una obra, como en el caso del descubrimiento de las improntas y los símbolos de color rojo encontrados durante la consolidación y restauración de la "palestra» de la villa Adriana a Tivoli ${ }^{64}$. El análisis de estos signos particulares, elaborado con un gran rigor metodológico, ha permitido comprender distintos elementos del proceso de construcción: los sistemas de nivelación para el desarrollo de las distintas etapas de planteamiento de las delimitaciones estructurales del espacio; los desniveles presentes en la ejecución de los muros; las modalidades del desarrollo del trabajo recuperado a partir de la distribución de las marcas en las paredes. Es interesante destacar cómo un conjunto de huellas aparentemente sin significado puede restituir una amplia porción de historia constructiva del espacio, sin el empleo de un análisis estratigráfico tradicional. La conservación de estos detalles de la obra permite, en cambio, establecer la existencia de prácticas edilicias sistemáticas y coordinadas, basadas en la materialización de las disposiciones de quien realiza el proyecto arquitectónico ${ }^{65}$, facilitando la transmisión directa y sin posibilidades de errores para la construcción de un determinado complejo.

La lectura de distintos factores técnico-constructivos presentes en las estructuras, ha permitido el reconocimiento de la dinámica de la obra en edificios estudiados tradicionalmente desde la óptica artística o, simplemente tipológica (el teatro de Itálica). En este caso específico, la reconstrucción del proyecto arquitectónico y la evolución del edificio se han realizado mediante el análisis de la decoración arquitectónica. Esta vinculación entre el esqueleto del edificio y su piel representa una asignatura pendiente de nuestro campo de estudio, visto que, en la mayoría de los casos, la investigación de los detalles

\footnotetext{
${ }^{63}$ En raros casos se han podido realizar excavaciones arqueológicas específicas orientadas a la reconstrucción de la estratigrafía contemporánea a la organización de una obra. En este sentido, véase la aportación modélica de Broquier-Reddé, V. 2008: pp. 309-320.

${ }^{64}$ Attoui, R. 2008: pp. 49-66

${ }_{65}$ Attoui, R. 2008: pp. 64-66.; improntas parecidas se han documentado también en la construcción de las termas de Itálica, véase Bukowiecki, E Dessales, H. 2008b: pp. 201-202.
} 
técnicos de la construcción se mueve en un terreno poco apto al arqueólogo clásico, interesado en los aspectos artísticos y en los procesos evolutivos de los elementos arquitectónicos. Desde esta perspectiva, una de las intervenciones presentadas en la primera reunión científica de Mérida ${ }^{66}$ ha puesto de manifiesto la importancia de una lectura homogénea de fenómenos que, en la mayoría de los casos, se planifican con planteamientos teóricos-metodológicos distintos.

En el ámbito de la cuantificación y diversificación de la mano de obra es necesario comprender cómo se programa un edificio; cuántas figuras profesionales intervienen, y cuáles se emplean para estructuras de distinta tipología. En definitiva, ¿cómo se gestiona la intervención de mano de obra especializada en relación con el desarrollo del trabajo? La cuantificación del mismo es fundamental para comprender la relación entre las distintas fases de ejecución de las partes estructurales de un edificio, visto que cada una necesita de elaboraciones específicas que responden a formas, tiempos y modalidades concretas.

La observación de algunos detalles como los signos de nivelación citados anteriormente ${ }^{67}$ nos ilustran los mecanismos de coordinación de distintos grupos de trabajo que además, aseguran a la obra un comportamiento estático homogéneo en las delicadas fases de secado de los morteros o la programación sistematizada de andamios, aperturas, etc.

Se han extraído conclusiones relativas al establecimiento de los tiempos de realización de estructuras complejas basadas en hallazgos excepcionales, como el caso de las termas de Trajano. Se han establecido los tiempos de realización de determinadas secciones de las estructuras, a raíz del descubrimiento de una serie de fechas de color rojo con la indicación de la apertura y finalización de la obra y de las distintas jornadas de trabajos necesarias ${ }^{68}$.

Desde esta perspectiva de estudio es necesario incorporar datos relacionados con la cuantificación del trabajo diario y los posibles condicionantes presentados en el desarrollo del mismo, ligados éstos últimos a la propia dinámica del proceso constructivo, o a los cambios del proyecto y las soluciones técnicas aportadas en la ejecución de la obra.

En esta línea, existen ya varios ensayos que plantean una serie de cálculos para evaluar las cantidades de mano de obra, materiales y trabajo en el ámbito del mundo de la

\footnotetext{
${ }^{66}$ Rodríguez Gutiérrez, O. 2008: pp. 209-228.

${ }^{67}$ Véase notas 65, 66.

${ }^{68}$ Volpe, R. 2002b: pp. 377-394.
}

construcción. Entre el primer y el segundo seminario (Mérida 2007 y Siena 2008) se han multiplicado los esfuerzos en este sentido. A un primer trabajo sobre un pórtico de Saint-Romain-en-Gal ${ }^{69}$ se han añadido otros de diferente adscripción cronológica y espacial.

\section{Aspectos productivos, sociales y económicos}

La aplicación de la metodología de la Arqueología de la Arquitectura para el registro y la caracterización de las técnicas edilicias ha permitido, en el caso de la zona costera de la Toscana ${ }^{70}$, efectuar un ensayo de gran interés sobre la continuidad, las rupturas, y la transmisión de los conocimientos tecnológicos en épocas y contextos productivos muy diferentes (época romana y altomedieval). La unión entre técnicas constructivas tratadas tradicionalmente con parámetros distintos y con metodologías antitéticas restituye un panorama que testimonia la existencia de elementos formales y soluciones tecnológicas que no presentan, en absoluto, la diversidad que se le atribuye desde un planteamiento tipológico distante (época romana y altomedieval).

Desde una óptica más general además se ha empezado a dar importancia a las relaciones sociales y jurídicas de las figuras profesionales de la edilicia romana ${ }^{71}$, continuando una línea propuesta en el seminario de París de 2006, que se desarrollará en el último encuentro planteado en la misma ciudad en Diciembre de 2009.

Con la excepcionalidad de algunos datos y ante la falta de fuentes directas de información, es posible establecer los términos y las condiciones del trabajo. En el caso de las termas de Trajano, por ejemplo, se ha comprobado que no existía descanso en el proceso de construcción de las subestructuras y se plantea la existencia de turnos laborales entre los encargados de la construcción y los responsables ${ }^{72}$. Estos aspectos, útiles para la determinación de los tiempos de las distintas fases de obra, se asoman al campo social del mundo de la construcción $y$, a pesar de no poder relacionar las condiciones del trabajo de una estructura fundada en una economía esclavista con la economía actual, es posible conocer algunos elementos añadidos a la compleja organización de la mano de obra.

Esta visión técnica de la arquitectura ha permitido observar la modalidad del cambio en las técnicas de

\footnotetext{
${ }^{69}$ Prisset, J. L. 2008: pp. 127-141.

${ }^{70}$ Pais, A. 2008: pp. 67-88.

${ }^{71}$ Mar, R. 2008: pp. 177-192.

${ }^{72}$ Volpe, R. 2002 b: p. 387
} 
construcción y la relación entre los materiales disponibles y los conocimientos tecnológicos implicados en los procesos constructivos de los edificios públicos. El caso de Carteia ha restituido, por ejemplo, una serie de interesantes informaciones sobre los efectos urbanísticos y las elecciones arquitectónicas en distintos periodos históricos, la época púnica, la fase republicana y la edad augustea ${ }^{73}$. Se trata en estos casos de saber vincular los cambios arquitectónicos y tecnológicos con la entidad de los promotores de la construcción, resaltando la tipicidad de las estructuras en base a las exigencias de la misma promoción. Se generan, así, tipologías distintas en relación con las prioridades urbanísticas, desde el ámbito militar, la integración o sustitución de tipos edilicios, o la propaganda imperial.

La elección topográfica de las grandes obras públicas plantea la problemática del impacto de la obra en la ciudad y viceversa. En muchos casos, al hacer la diacronía de los hechos urbanos se pierden los datos que marcan los elementos perdidos de la historia de los espacios. Consideramos esa historia o la de un edificio como historias de uso/trasformación/abandono, perdiendo los elementos y los tiempos previos que llevan a poder utilizar un conjunto construido $^{74}$. Estos pasajes indican a veces arcos cronológicos de 30/40 años, relativos a la duración de una o más obras de gran envergadura abiertas al mismo tiempo, que convierten las ciudades en autenticas áreas de trabajo por tiempos muy largos generando un paisaje lejano y complejo respecto a la imagen de templos, foros y teatros realizados en un mismo orden cronológico. Entre los problemas organizativos más comunes de una ciudad en obra no es necesario hacer un listado completo y se indican, solamente la limitación de las vías de tránsito y los cambios de circulación, elementos que de forma prolongada, cambian completamente la fisonomía urbanística. Otros problemas generan la existencia en las inmediaciones de otros espacios vinculados con las áreas de almacenamiento y distribución de los materiales, cercanos a las obras para no aumentar la cantidad de tráfico de carros de transporte al interior de la ciudad ${ }^{75}$.

La temática del impacto ambiental de una obra respecto a la ciudad antigua se vincula a los factores citados $\mathrm{y}$ es otra asignatura pendiente que sería útil proponer como argumento para futuras reuniones. El estudio de la relación entre los materiales procedentes de las demolicio-

\footnotetext{
${ }^{73}$ Bendala, M. - Roldán, L. - Blánquez, J. 2008: pp. 229-242.

${ }^{74}$ Véase en general Mateos Cruz 2006.

${ }^{75}$ Amici, C. M. 2008: pp. 13-32.
}

nes y la reutilización en las nuevas edificaciones o en proyectos distintos, no siempre constituye un elemento de interés. En este sentido es necesario empezar a formular alguna pregunta. ¿Cuál es el uso de los materiales resultantes de las demoliciones de contextos arquitectónicos privados en la edilicia pública y viceversa? ¿Existía un reempleo sistemático o estructuras relacionadas con la gestión de los residuos constructivos?

Estas cuestiones confluyen directamente en la reconstrucción de los aspectos económicos de las obras edilicias, argumento que será objeto del último seminario de «arqueología de la construcción» que tendrá lugar en París en diciembre de 2009. El objetivo de este último encuentro es la evaluación del impacto de las obras públicas y privadas en la economía de una ciudad romana provincial. Para conjuntos específicos como el caso de Volúbilis se ha intentado ya en el encuentro de Mérida, establecer una serie de pautas para una reflexión económica sobre la envergadura y comparación del ámbito público y priva$\mathrm{do}^{76}$. En este caso, una parte de los datos para la reconstrucción del citado aspecto se ha extraído del análisis epigráfico y al mismo tiempo se ha realizado un ensayo paralelo sobre los restos arqueológicos que ha integrado las informaciones escritas con resultados concretos, permitiendo la formulación de hipótesis generales sobre el funcionamiento de las obras y la economía implicada. Este estudio es de gran interés debido a la precisión de los datos restituidos y, sobre todo, por las implicaciones sociales del mundo de la construcción, establecidas en base a la identidad y al papel desarrollado por los promotores de la obra.

Entre las perspectivas futuras, además, es necesario señalar el establecimiento de una metodología de registro común y una homogeneización de los elementos que permitan reconstruir la historia de la industria edilicia romana, organizando los datos sobre la producción y la gestión de las obras en un contexto más general y amplio que permita efectuar otro paso hacia la comprensión de los mecanismos económicos que las determinan. Sin este proceso de homogeneización será difícil crear un contenedor más amplio de estudios específicos sobre territorios concretos que puedan ser objeto de comparación.

El laboratorio que se ha abierto respecto a las temáticas citadas presenta alguna asignatura pendiente que, necesariamente, tendrá un papel relevante en los encuentros y trabajos futuros. La recopilación y organización de una amplia serie de datos sobre los aspectos de la construc-

${ }^{76}$ Camporeale, S. - Papi, E. - Passalacqua, L. 2008: pp. 285-308. 
ción en época romana, los procesos de cuantificación y análisis de las dinámicas de las obras, la tipología de técnicas y actividades edilicias tiene que volver la mirada hacia la comprensión de los procesos productivos de la actividad constructiva en la antigüedad. En un sentido general, la reconstrucción de la obra no concluye con el registro de los datos de esa actividad. Las informaciones obtenidas confluyen obligatoriamente en el contenedor más amplio de los fenómenos históricos generales, convirtiéndose en elementos de conocimiento fundamentales para interpretar las innumerables connotaciones sociales y económicas de cada proceso constructivo.

En este ámbito existen, además, una amplia serie de contribuciones y de intereses científicos nuevos vinculados estrictamente con la temática productiva de la industria edilicia romana que enriquecen las tradicionales visiones estilísticas con detalles fundamentales para el conocimiento de un edificio.

En conclusión, creemos que el estudio de las dinámicas edilicias necesita de una aproximación global y de un nuevo interés de la Arqueología Clásica que conduzca a la consideración de una obra desde la óptica de un proceso productivo y no sólo como un elemento artístico.

Las ideas enunciadas sobre organización y gestión necesitan una profundización teórica nueva, en relación con el perfeccionamiento de las técnicas de registro de los parámetros y los procedimientos que permiten el reconocimiento de las actividades en conexión con la construcción. Con los seminarios organizados se ha intentado poner las bases de una reflexión nueva sobre estos argumentos y, sobre todo, se ha buscado un denominador común para la documentación correcta de todas las informaciones relativas a la complejidad de una obra edilicia en contextos tradicionalmente orientados a ignorar estas temáticas.

\section{Bibliografía}

Amici, C. M. 2008: «Dal monumento all'edificio: il ruolo delle dinamiche di cantiere». En Camporeale, S. - Dessales, H. - Pizzo, A. (eds.) 2008, pp. 1332, Madrid.

Arenillas, M. - Segura, C. - Bueno, F. - Huerta, S. (eds.) 2007: Actas del Quinto Congreso Nacional de Historia de la Construcción. Cádiz, 79 de junio de 2007 Madrid.

Attoui, R. 2008: «Segni di cantiere nella 'palestra' di Villa Adriana Tivoli». En Camporeale, S. - Dessales, H. - Pizzo, A. (eds.) 2008, pp. 49-66, Madrid.

Azkarate Garai-Olaun, A. 2002: "Intereses cognoscitivos y praxis social en Arqueología de la Arquitectura», Arqueología de la Arquitectura I, 2002, pp. 55-71.

Azkarate, A. - Cámara, L. - Lasagabaster, J. A. - Latorre, P. 2001: Catedral de Santa Maria.Vitoria-Gasteiz. Plan Director de Restauración, Vitoria.

Azkarate, A. - Quirós, J. A. (eds.) 2005: Aparejos constructivos medievales en el Mediterraneo Occidental. Estudio arqueológico de las técnicas constructivas, Arqueología de la Arquitectura 4, Vitoria.
Barresi, P. 2008: «I capitoli di Sufetula e di Baelo Claudia: analisi dei progetti. En Camporeale, S. - Dessales, H. - Pizzo, A. (eds.) 2008, pp. 259-268, Madrid. Bendala Galán, M. 1992: «Materiales de construcción romano: peculiaridades de España", Ciencia, metodologías y técnicas aplicadas a la arqueología (Rodá, I. Ed.), pp. 215-226, Barcelona.

Bendala Galán, M. - Durán, R. 1994: «El anfiteatro de Augusta Emerita: rasgos arquitectónicos y problemática urbanística y cronológica, El anfiteatro en la Hispania romana (Coloquio Internacional, Mérida, 26-28 de Noviembre de 1992), pp. 247-264.

Bendala, M. - Rico, C. - Roldán, L. (eds.) 1998: El ladrillo y sus derivados en la época romana, Madrid.

Bendala, M. - Roldán, L. - Blánquez, J. 2008: «La arquitectura augustea en Carteia. Sus peculiaridades técnicas y formales» «. En Camporeale, S. Dessales, H. - Pizzo, A. (eds.) 2008, pp. 229-242, Madrid.

Bessac, J. C. 1986: L'outillage traditionnel du tailleur de pierre de 1 'antiquité è nos jours, CNRS, Paris.

Bessac, J. C. 1999: «Pierres de taille: archeologie et technique», La Construction en pierre (Ferdiere, A. Ed.), pp. 9-52, Paris.

Bessac, J. C. - Burnouf, J. - Journot, F. - Prigent, D. - Sapin, C. - Seigne, J. 1999: La construcción en pierre, Paris.

Bianchi, G. 1996: «Trasmissione dei saperi tecnici e analisi dei procedimenti costruttivi di etá medievale», Archeologia dell'Architettura I, 1996, pp. 53-64.

Bianchi, G. 1997: «I segni dei tagliatori di pietre negli edifici medievali. Spunti metodologici ed interpretativi», Archeologia dell'Architettura II, 1997, pp. 2537.

Bianchi, E. - Meneghini, R. 2002: «Il cantiere costruttivo del foro di Traiano», Cantieri Antichi. Giornata di studio tenuta il 25 Ottobre 2001, RM, 109, pp. 395-417, Roma.

Binninger, S. 2008: «La construction du trophée d'Auguste à La Turbie : l'étude de l'organisation et des rythmes du chantier ». En Camporeale, S. - Dessales, H. - Pizzo, A. (eds.) 2008, pp. 89-106, Madrid.

Bores Gamundi, F. - Fernández Salas, J. - Huerta Fernández, S. - Rabasa Díaz, E. (eds.) 1998: Historia de la Construcción (Actas del Segundo Congreso Nacional, A Coruña, 22-24 de octubre de 1998), Madrid.

Brissaud, L. 2008: «La construction des thermes des Lutteurs: regards croisés sur un chantier urbain antique et son impact sur la ville (Saint-Romain-en-Gal, France)». En Camporeale, S. - Dessales, H. - Pizzo, A. (eds.) 2008, pp. 107124, Madrid.

Brogiolo, G. P. 1988: Archeologia dell'edilizia storica, Como.

Brogiolo, G. P. 1996: «Prospettive per l'archeologia dell'architettura», Archeologia dell'Architettura I, 1996, pp.11-15.

Brogiolo, G. P. 2002: «L'Archeologia dell'Architettura in Italia nell'ultimo quinquenio", Arqueologia de la Arquitectura, I, 2002, pp. 19-26.

Brogiolo; G. P. - Zonca, A. 1989: "Residenze medievali (XI-XII secc.) nel territorio lombardo", Storia della città, 52, pp. 37-44.

Brouquier-Reddé, V. 2008 : "Chantiers de construction de sanctuaires en Gaule et en Afrique á l'epoque romaine: un bilan des données récentes ", En Camporeale, S. - Dessales, H. - Pizzo, A. (eds.) 2008, pp. 309-320, Madrid.

Bukowiecki, E. - Dessales, H. - Dubouloz, J. (Coords.) 2006: http:// www.diffusion.ens.fr $/$ index.php? res $=$ cycles $\&$ idcycle $=276$

Bukowiecki, E - Dessales, H. - Dubouloz, J. 2008 : Château d'eau et élements du rescau d'adduction, Collection de l'École Française de Rome, 402.

Bukowiecki, E - Dessales, H. 2008a : «Un système d'enregistrement appliqué à Ostie (EB, HD)». En Bukowiecki, E - Dessales, H. Dubouloz, J. 2008 : Château d'eau et élements du rescau d'adduction, Collection de l'École Française de Rome, 402, pp. 24-39.

Bukowiecki, E. - Dessales, H. 2008b: «Les thermes publics d'Itálica : regards comprés sur deux chantiers de construction ". En Camporeale, S. - Dessales, H. - Pizzo, A. (eds.) 2008, pp. 191-208, Madrid.

Caballero Zoreda, L. 1987: «El método arqueológico en la comprensión del edificio. (Sustrato y estructura)", Curso de Mecánica y tecnología de los edificios antiguos, Colegio Oficial de Arquitectos de Madrid, pp. 13-58.

Caballero Zoreda, L. 1996: «El análisis estratigráfico de construcciones históricas", Arqueología de la Arquitectura. El metodo arqueológico aplicado al proceso de estudio y de intervención en edificios históricos (Caballero Zoreda, L. Escribano Velasco, C. Eds.), pp. 55-74, Burgos. 
Caballero Zoreda, L. 1999: «Aportación a la arquitectura medieval española. Definición de un grupo de iglesias castellanas, riojanas y vascas", Actas del $V$ Congreso de Arqueología Medieval Española (Valladolid), 1, pp. 221-233.

Caballero Zoreda, L. 2002: «Sobre límites y posibilidades de la investigación arqueológica de la arquitectura. De la estratigrafía a un modelo histórico», Arqueología de la Arquitectura I, 2002, pp. 83-100.

Caballero Zoreda, L. 2004: «Una experiencia en la Arqueología de la Arquitectura», Arqueología de la Arquitectura 3, 2004, pp. 127-143.

Caballero Zoreda, L. - Escribano Velasco, C. 1996 (Eds.): Arqueología de la Arquitectura. El metodo arqueológico aplicado al proceso de estudio y de intervención en edificios históricos, Burgos.

Caballero Zoreda, L. - Fernández Mier, M. 1997: «Análisis arqueológico de construcciones históricas en España. Estado de la cuestión», Archeologia dell'Architettura II, 1997, L'archeologia del costruito in Italia e in Europa. Esperienze a confronto e orientamenti della ricerca (Atti della Giornata di Studi, Genova 10 Maggio 1996), pp. 147-158.

Caballero, L. - Murillo Fragero, J. I. 2004: «Como se construye una torre mudéjar. La torre de la iglesia de San Pedro el Viejo de Madrid». En Arqueología de la Arquitectura 3, pp. 39-56, Vitoria.

Camporeale, S. - Dessales, H. - Pizzo, A. (eds.) 2008: Arqueología de la Construcción I. Los procesos constructivos en el mundo romano: Italia provincias y occidentales, (Mérida, Instituto de Arqueología 25-26 de Octubre de 2008), Anejos de Archivo Español de Arqueología no 50, Madrid.

Camporeale, S. - Dessales, H. - Pizzo, A. 2008: «Introducción». En: Camporeale, S. - Dessales, H. - Pizzo, A. (eds.) 2008, pp. 9-12, Madrid.

Camporeale, S. - Dessales, H. - Pizzo, A. (eds.) 2009 e.p. Archeología della Costruzione II. I cantieri edili nel mondo romano. Italia e province orientali (Siena, Certosa di Pontignano 13-15 Novembre 2008), Anejos de Archivo Español de Arqueología no ¿?, Madrid.

Camporeale, S. - Papi, E. - Passalacqua, L. 2008: «L'organizzazione dei cantieri a Volubilis (Mauretania Tingitana): iscrizioni e opere pubbliche, la maison aux deux pressoirs, l'arco di caracalla». En: Camporeale, S. - Dessales, H. - Pizzo, A. (eds.) 2008, pp. 285-308, Madrid.

Cantieri Antichi. Giornata di studio tenuta il 25 Ottobre 2001, RM, 109, 2002, pp. 340-429, Roma.

Casas Gómez, A. - Huerta Fernández, S. - Rabasa Díaz, E. (eds.) 1996: Historia de la Construcción (Actas del Primer Congreso Nacional, Madrid, 19-21 de septiembre de 1996), Madrid.

Delaine, J. 1997: The Baths of Caracalla. A study in the design, cosntruction and economics of large-scale building projects in imperial Rome, JRA suppl. 25, Portsmouth, RI.

Delaine, J. 2003: «The builders of Roman Ostia: organisation, status and society". En Proceedings of the First International Congres on Construction History (Madrid, 20-24/1/2003) vol 2, pp. 723-732, Madrid.

Delaine, J. 2007: «The cost of creation: technology at the service of construction». En Lo Cascio, E. (ed.) Innovazione técnica e progresso económico nel mondo romano, Pragmateiai 10 pp. 237-252, Bari.

Delaine, J. 2008: «Conclusions», En: Camporeale, S. - Dessales, H. - Pizzo, A. (eds.). Arqueología de la Construcción I, pp. 321-328.

Dessales, H. 2008: «L'archéologie de la construction. Essai de définition " En Bukowiecki, E - Dessales, H. Dubouloz, J. (eds.) 2008 : Château d'eau et élements du rescau d'adduction, Collection de l'Ecole Français de Rome, 402, pp. 19-24.

De Vos, M. 2008: «Caratteristiche della costruzione degli impianti produttivi rurali nell'Africa Proconsularis» En: Camporeale, S. - Dessales, H. - Pizzo, A. (eds.), pp. 269-284, Madrid.

Dunkeld, M. - Campbell, J. - Louw, H - Tutton, M - Addis, B. - Thorne, R. (eds.) 2006: Second international congress on Construction History. Queens' College Cambridge University, 29th March - 2nd April 2006,Cambridge.

Durán Cabello, R. 1991-1992: «Técnicas de edilicia romana en Mérida I», Anas, 4/5, pp. 45-80, Mérida.

Durán Cabello, R. 1998: La última etapa del teatro romano de Mérida. La versura oriental y los sellos latericios, Mérida.

Durán Cabello, R. 2004: El teatro y el anfiteatro de Augusta Emerita. Contribución al conocimiento histórico de la capital de Lusitania, Oxford.

Esquieu, Y. 1997: «L'archeologie du Batí en France», Archeologia dell'Architettura
II, 1997, Larcheologia del costruito in Italia e in Europa. Esperienze a confronto e orientamenti della ricerca (Atti della Giornata di Studi, Genova 10 Maggio 1996), pp. 133-140.

Francovich, R. - Parenti, R. (Eds.) 1988: Archeologia e Restauro dei monumenti, (Pontignano 1987), Firenze.

Gabbrielli, F. 1996: «La cronotipología relativa come metodo di analisi degli elevati: la facciata del Palazzo Pubblico di Siena»; Archeologia dell'Architettura I, pp. 17-40.

Giuliani, F. C. 2002: «Cantiere e conoscenza». En: Cantieri Antichi. Giornata di studio tenuta il 25 Ottobre 2001, $R M$, 109, 2002, pp. 340-429, Roma.

Giuliani, F. C. 2008: «Sfidando gli inferi: problemi di cantiere dell’emissario del Fucino». En Camporeale, S. - Dessales, H. - Pizzo, A. (eds.) 2008, pp. 33-47, Madrid.

Graciani García, A. - Huerta Fernández, S. - Rabasa Díaz, E. - Tabales Rodríguez, A. (eds.) 2000: Historia de la Construcción (Actas del Tercer Congreso Nacional, Sevilla, 26-28 de octubre de 2000). Madrid.

Guyard, L. - Bertrudiére, S. - Cormier, S. - Coutelas, A. 2008 : « Le chantier de construction des thermes gallo-romains du vieil-Evreux (Eure) : entre preuves et indices ». En Camporeale, S. - Dessales, H. - Pizzo, A. (eds.) 2008, pp. 155-174, Madrid.

Huerta Fernández, S. (ed.) 2003. Proceedings of the First International Congress on Construction History (Madrid 20th-24 th January 2003). Madrid.

Huerta Fernández, S. (ed.): 2005: Actas del Cuarto Congreso Nacional de Historia de la Construcción. Cádiz, 2729 de enero de 2005 Madrid.

Hobel, S. E. 1989: «Pietre segnate e marche muratorie. Testimonianza delle confraternite iniziatiche e di mestiere", Actes Internationales du VI Colloque International de Glyptographie de Samoèns, ( 5-10 Luglio 1988), pp. 263-290, Braine-le Château.

Journot, F. 1999: «Archéologie du Bâti», Ferdiere, A. (Ed.) 1999: La construction en pierre, pp. 133-163, Paris.

Mannoni, T. 1974: «L'analisi delle tecniche murarie medievali in Liguria», Atti del colloquio internazionale di Archeologia Medievale, pp. 291-300, Erice 1974, Palermo 1976.

Mannoni, T. - Boato, A. 2002: «Archeologia e storia del cantiere di costruzione», Arqueología de la Arquitectura I, 2002, pp. 39-53.

Mar, R. 2008: «La construcción pública en las ciudades hispanas. Los agentes de la construcción». En Camporeale, S. - Dessales, H. - Pizzo, A. (eds.) 2008, pp. 175-190, Madrid.

Mateos Cruz, P. 2006 (Ed.): El «foro provincial» de Augusta Emerita: un conjunto monumental de culto imperial, Anejos de AEspA XLII, Madrid.

Mateos, P. - Pizzo, A. 2008: «La costruzione del 'foro provinciale' di Augusta Emerita». En Camporeale, S. - Dessales, H. - Pizzo, A. (eds.) 2008, pp. 243258, Madrid.

Morriss, R. K. 2000: The Archeology of Buildings, Stroud.

Pais, A. 2008: «L'edilizia romana nella toscana tirrenica alla luce dell'archeologia dell'architettura». En Camporeale, S. - Dessales, H. - Pizzo, A. (eds.) 2008, pp. 67-88, Madrid.

Parenti, R. 1988: «Le tecniche di documentazione per una lettura stratigrafica dell'elevato", Archeologia e restauro dei monumenti (Francovich, R. - Parenti, R. 1988 Eds.), pp. 249-279, Firenze.

Parenti, R. 2002: "Dalla stratigrafía all'archeologia dell'architettura. Alcune resentí esperienze del laboratorio senese», Arqueología de la Arquitectura I, 2002, pp. 73-82.

Paron I. - Reveyron N. (dir.) 2005 : Archéologie du bâti. Pour une harmonisation des méthodes, Actes de la table ronde (Saint-Romain-en-Gal, 9-10 nov. 2001), Paris.

Paron-Kontis, I. 2005 : «Unités de construction et objets archéologiques ». En Paron I., Reveyron N. (dir.) 2005 : Archéologie du bâti. Pour une harmonisation des méthodes, Actes de la table ronde (Saint-Romain-en-Gal, 9-10 nov. 2001), pp. 13-18, Paris.

Pringent, D. - Hunot, J. Y. 2000: «Archéologie et monuments historiques,» Dossiers d'Archéologie, 250, pp. 72-75.

Prisset, J. L. 2008: "Les besoins en matériaux, les contraintes d'approvisionnement et la durée d'u chantier de construction. Réflexions à partir du portique nord de Saint-Romain-en-Gal (France)». En Camporeale, S. Dessales, H. - Pizzo, A. (eds.) 2008, pp. 125-140, Madrid. 
Rea, R. - Beste, H. J. - Lancaster, L. 2002: «Il cantiere del Colosseo», Cantieri Antichi. Giornata di studio tenuta il 25 Ottobre 2001, RM, 109, 2002, pp. 341-375, Roma.

Rodríguez Gutierrez, O. 2004: El teatro romano de Itálica. Estudio arqueoarquitectónico, Madrid.

Rodríguez Gutiérrez, O. 2008: «El proceso de edificación del teatro romano de Itálica a través del análisis arqueológico de sus diferentes etapas constructivas", En Camporeale, S. - Dessales, H. - Pizzo, A. (eds.) 2008, pp. 209-228, Madrid.

Roldán Gómez, L. 1987: «Aproximación metodológica al estudio de la técnica edilicia romana en Hispania, en particular el opus testaceum», Lucentum, VI, 1987, pp. 101-122.

Roldán Gómez, L. 1992: Técnicas constructivas romanas en Carteia (San Roque, Cadiz), Madrid.

Roldán Gómez: L. 1994: Técnicas constructivas romanas en Italica, Madrid.

Roskams, S. (Ed.) 2000: Interpreting Stratigraphy. Site evaluation, recording procedures, and stratigrafhic analysis. Papers presented to the Interpreting Stratigraphy Conferences 1993-1997, British Archaeological Reports, International Series, 910. Oxford.
Utrero Agudo, M.a Á. 2006: Iglesias tardoantiguas y altomedieval en la Peninsula Ibérica. Análisis arqueologico y sistemas de abovedamiento, Anejos de Archivo Español de Arqueología, XL, Madrid.

Utrero Agudo, M. a Á. 2008: «Arqueología de la Arquitectura y patrimonio edificado. Experiencias y perspectivas una década después». En La investigación sobre Patrimonio Cultural (C. Sáiz Jiménez - M.A. Rogelio Candelero eds.), Sevilla.

Volpe, R. 2002: "Premessa» a Cantieri Antichi. Giornata di studio tenuta il 25 Ottobre 2001, $R M$, 109, p. 339, Roma.

Volpe, R. 2002b: "Un antico giornale di cantiere delle terme di Traiano", Cantieri Antichi. Giornata di studio tenuta il 25 Ottobre 2001, RM, 109, 2002, pp. 377-394, Roma.

Wilson Jones, M. 2000: Principles of Roman Architecture, New Haven-London. Wood, J. 1994: Building Archaeology. Applications in Practice, Oxford.

Recibido: 30 de abril de 2009 Aceptado: 30 de septiembre de 2009 